\title{
Evidence on the stability of histone H1.a polymorphic variants during selection in quail
}

\author{
Andrzej Kowalski ${ }^{1}$ and Sebastian Knaga ${ }^{2}$ \\ ${ }^{1}$ Department of Biochemistry and Genetics, Institute of Biology, Jan Kochanowski University, Kielce, Poland \\ ${ }^{2}$ Chair for Biological Bases of Animal Production, University of Life Sciences in Lublin, Lublin, Poland
}

Correspondence to: Andrzej Kowalski (a.kowalski@ujk.edu.pl)

Received: 23 January 2017 - Revised: 22 April 2017 - Accepted: 5 May 2017 - Published: 9 June 2017

\begin{abstract}
The goal of this work was to check whether selection for quantitative traits may cause a change in the histone $\mathrm{H} 1$ allelic complement and whether it can therefore be considered a modulator of histone H1-dependent chromatin functioning. For this purpose, a fluctuation of histone H1.a polymorphic variants was analyzed among a non-selected (control) quail line and the line selected for a high cholesterol content in the egg yolk. The histone H1.a was found to be polymorphic due to its differential migration rate in the AU-PAGE (acetic acidurea polyacrylamide gel electrophoresis). Based on this, two H1.a isoforms (H1.a1 and H1.a2) that form three phenotypes (a1, a2 and a1a2) were distinguished in the quail lines tested. A comparably expressed $(p>0.05)$ and low relative variable (coefficient of variation, $\mathrm{CV}<0.25$ ) histone H1.a phenotypes were in agreement with Hardy-Weinberg equilibrium (HWE) in both the non-selected $\left(\chi^{2}=1.29, p=0.25\right)$ and selected $\left(\chi^{2}=1.9\right.$, $p=0.16)$ quail line. The similarity among quail lines was assessed based on the equal distribution of histone H1.a phenotypes $\left(\chi^{2}=1.63, p=0.44\right)$ and alleles $\left(\chi^{2}=0.018, p=0.89\right)$ frequency in both quail lines tested. This indicates that selection does not affect the histone H1.a polymorphic variants. The stability of histone H1.a during selection might suggest that likely chromatin processes coupled to the selected trait are not linked to the activity of histone H1.a.
\end{abstract}

\section{Introduction}

Chromatin functioning is heavily dependent on the activity of histone proteins, of which the H1 histone participate in the formation of its structure both at the nucleosomal and a higher-order organization level (Woodcock and Ghosh, 2010; Crane-Robinson, 2016). Histone H1 binds to the linker DNA at the entry/exit site of the nucleosome and assist in folding of the basic $(10 \mathrm{~nm})$ nucleosome fiber into a higher-order $(30 \mathrm{~nm})$ chromatin structure (Hansen, 2012). The different structure and topology of chromatin and, therefore, its distinct functioning is determined by histone H1-DNA binding. Whereas the on-dyad axis location creates more compacted (transcriptionally inert) chromatin conformation, the off-dyad axis position forms more loosened (transcriptionally capable) chromatin structure (Zhou et al., 2015). Moreover, the mode of histone $\mathrm{H} 1$ binding to the DNA is determined by its C-terminal (Th'ng et al., 2005) and globular
(Piscopo et al., 2010) domain and may be different in distinct cell types. Due to the presence of the arginine residues, the sperm H1-like histones are able to form aggregates and highly condensed DNA in comparison to the somatic H1 histones deprived of arginine and are thus unable to selfassociate and create highly packaged DNA (Salvati et al., 2008). Therefore, histone H1 influences gene expression, regulating the access of transcription factors to the target DNA sequences (Herghet and Schneider, 2015). As a consequence, histone $\mathrm{H} 1$ is engaged in a range of activities, including cell cycle regulation and cellular response as well as repair of damaged DNA and transmission of the apoptotic signals (Roque et al., 2016). Moreover, the scope of histone H1 activity is broader due to its interactions with varied proteins of both nuclear (McBryant et al., 2010) and nucleolar (Kalashnikova et al., 2016) localization.

All of the $\mathrm{H} 1$ histone functions are realized by a set of non-allelic subtypes that might act individually or in com- 
mon, due to the redundant effect compensating for downregulation and/or a lack of some $\mathrm{H} 1$ subtypes (Millãn-Ariño et al., 2016). A specific activity of histone H1 subtypes, possessing characteristic genomic distribution (Izzo et al., 2013) and distinct rate of the mobility (Th'ng et al., 2005), is related to the differences in the ability to bind DNA and condense chromatin. The data originating from distinct reports (for a review, see Kowalski and Pałyga, 2016) indicate that the strong (histone H1.4 and H1.5), intermediary (histone H1.3) and weak (histone H1.1 and H1.2) chromatin condensers can be distinguished within the mammalian histone H1 subtypes. However, both common and individual impact on gene expression is characteristic for $\mathrm{H} 1$ histones. Whereas histone H1.0 controls genes involved in the amino acid metabolism and protein synthesis, the histone H1.c affects genes responsible for DNA replication and recombination. In contrast, the genes associated with cell cycle are regulated by both histone H1.c and H1.0 (Bhan et al., 2008).

The complement of histone $\mathrm{H} 1$ counts several non-allelic subtypes non-uniformly distributed in the somatic cells of various organisms and species. There are also $\mathrm{H} 1$ subtype expressions which are confined to the specialized tissue and to the stage of cell differentiation (Parseghian, 2015; Kowalski and Pałyga, 2016). Mammalian histone H1 non-allelic subtypes are ubiquitously expressed in the somatic cells (H1.1, H1.2, H1.3, H1.4, H1.5, H1.0 and H1.10) and also characteristic for germ cells, present in the sperm (H1t, H1T2 and HILS1) and in the oocyte (H1oo) (Happel and Doenecke, 2009). The expression of histone H1.0 progresses during differentiation and achieves a maximal level in the terminally differentiated cells (Kowalski, 2016a), much like the avian histone H1 subtype H5, which is highly accumulated in the completely differentiated erythrocyte (Kowalski and Pałyga, 2011). Among the remaining H1 histones in birds, the subtypes H1.a, H1.b, H1.c, H1.c' and H1.d were found as ubiquitous, contrary to the species-specific subtypes H1.a', H1.b' and H1.z (Kowalski and Pałyga, 2017). Whereas histone H1.c' has not been identified to date as polymorphic, the rest of the $\mathrm{H} 1$ subtypes show heterogeneity due to different abundance (i.e., protein band and/or spot intensity) and localization (i.e., disparate net charge or molecular weight) in the polyacrylamide gels (Kowalski and Pałyga, 2012a). The avian histone $\mathrm{H} 1$ polymorphic variants are variously distributed in the breeding (Górnicka-Michalska et al., 2014; Kowalski and Pałyga, 2014), conservative (GórnickaMichalska et al., 2014; Kowalski and Pałyga, 2014) and wildliving (Kowalski et al., 2010, 2011; Kowalski, 2016b) populations, which reflects their correlation with some of the phenotypic (Pałyga et al., 2000; Kowalski and Pałyga, 2014) and physiological (Pałyga, 1998a; Kowalski et al., 2015) organismal features.

The alterations in the frequency of histone $\mathrm{H} 1$ alleles (Pałyga, 1998a) as well as disparate distribution of histone H1 genotypes and phenotypes (Kowalski et al., 2015) have already been reported in a response to the selection con- ducted with respect to different quantitative traits in the quail lines. The data reported in the current study indicate, however, that not all histone $\mathrm{H} 1$ polymorphic subtypes are sensitive to the selection. A neutral effect of selection was noted based on an almost equal distribution of histone H1 phenotypes at a locus H1.a between low genetically differentiated, control and selected, quail lines. Whereas no difference in the histone H1.a phenotypic diversity was detected, it seems that the expected selection-induced changes in the chromatin organization and functioning are not influenced by the polymorphic variants of histone H1.a.

\subsection{Materials and methods}

\subsubsection{Animals}

The Japanese quail (Coturnix japonica) population in this current study consisted of 37 unselected (control) birds and 41 birds selected for a high cholesterol content in the egg yolk. The birds were bred at the animal experimental station belonging to the Chair for Biological Bases of Animal Production of the University of Life Sciences in Lublin, Poland, after a relocation from the farm of the Slovak Agricultural Research Centre, Nitra, Slovak Republic. The birds were raised in collective cages (six birds in each) under continuous lighting (natural and artificial). The rearing temperature was gradually decreased: 38 to $34^{\circ} \mathrm{C}$ in the first week, 33 to $28^{\circ} \mathrm{C}$ in the second week, and 27 to $22^{\circ} \mathrm{C}$ in the third week. Afterward, it was maintained between 18 and $20^{\circ} \mathrm{C}$. The quail were fed ad libitum commercial diets according to age. A diet containing $24 \%$ crude protein (CP) and $2900 \mathrm{kcal}$ of metabolizable energy (ME) per kg was used for the first 28 days; the finisher ration had $20 \% \mathrm{CP}$ and $2800 \mathrm{kcal}$ of ME per kg. During production the quail were fed with a diet containing $21 \% \mathrm{CP}$ and $2800 \mathrm{kcal}$ of ME per $\mathrm{kg}$. Birds had free access to water during the experiment. Animal care and experimental procedures were in accordance with Polish and European regulations. All procedures were approved by the Local Ethical Commission for Animal Experiments in Lublin (permit number 50/2009).

\subsubsection{Blood sample collection and histone $\mathrm{H} 1$ extraction}

About $1 \mathrm{~mL}$ of whole blood was taken from a wing vein of a single bird to a tube containing a cooled solution of $0.15 \mathrm{M} \mathrm{NaCl}$ and $0.015 \mathrm{M}$ sodium citrate supplemented with $1 \mathrm{mM}$ phenylmethylsulfonyl fluoride (PMSF). After centrifugation of blood mixture and aspiration of the upper leukocyte layer, the isolated erythrocytes were purified by several suspensions and centrifugation in the same solution.

Erythrocyte nuclei were obtained by lysis in $3 \%$ saponin buffered with $0.1 \mathrm{M}$ sodium phosphate $(\mathrm{pH} 7.0)$ and washing in $0.9 \% \mathrm{NaCl}$. From freshly prepared erythrocyte nuclei, histones $\mathrm{H} 1$ were isolated by double extraction with perchloric acid solution, i.e., 1 and $0.5 \mathrm{M}$ (Neelin et al., 1995). The proteins were precipitated with $20 \%$ trichloroacetic acid and 
washed with acetone, acidified with $\mathrm{HCl}(500: 2, v / v)$ and acetone itself. From the air-dried preparations, histone H1 samples were prepared for electrophoresis by dissolving a $1 \mathrm{mg}$ protein aliquot in $100 \mu \mathrm{L}$ of the sample buffer $(8 \mathrm{M}$ urea, $0.9 \mathrm{M}$ acetic acid and $10 \%$ 2-mercaptoethanol).

\subsubsection{AU-PAGE}

H1 histones were resolved in a $24 \mathrm{~cm}$ long polyacrylamide slab gel containing $15 \%$ acrylamide, $0.5 \% \mathrm{~N}, \mathrm{~N}^{\prime}$ methylenebisacrylamide, $8 \mathrm{M}$ urea and $0.9 \mathrm{M}$ acetic acid (Kowalski and Pałyga, 2012b). The electrophoresis was conducted for $48 \mathrm{~h}$ at $150 \mathrm{~V}$ towards a cytochrome $\mathrm{C}$ used as a marker of the electrophoretic migration velocity. The separated proteins were routinely stained with the Coomassie Blue R-250 dye dissolved in the mixture of acetic acid (10\%) and propanol-2 (25\%) and visualized on the transparent gel background after several washes in the $10 \%$ acetic acid solution.

\subsubsection{Gel image processing and quantitative evaluation of histone $\mathrm{H} 1$.a phenotypes}

The patterns of $\mathrm{H} 1$ histones identified with AU-PAGE (acetic acid-urea polyacrylamide gel electrophoresis) were saved with the Doc-Print II gel imaging system (Vilber Lourmat). The captured images of histone H1.a isoforms were further analyzed with the use of ImageJ 1.44c software (www. rsbweb.nih.gov/ij). An area in square millimeters and a raw integrated density indicating the sum of the values of the pixels in the selected area were determined to evaluate the histone H1.a phenotypes' levels according to the size and intensities of their protein bands, respectively. The measurements were performed 10 times $(n=10)$ for individual histone H1.a isoforms corresponding to a given phenotype.

\subsubsection{Statistical analysis}

Testing for fit of quail populations to the Hardy-Weinberg equilibrium was done with the use of a chi-square $\left(\chi^{2}\right)$ test of goodness of fit. A difference between the levels of histone H1.a alleles and phenotypes was evaluated with the use of chi-square $\left(\chi^{2}\right)$ test of homogeneity. The levels of statistical significance were assumed at $p$ values less than 0.05. A relative variability of histone H1.a phenotypes was estimated by the values of coefficient of variation (CV) calculated as a ratio of standard deviation and the mean. The values less than 0.25 were recognized as equivalent to the low variability (Pernica et al., 2013). A genetic variation among quail lines was assessed using Wright's $F$-statistics indices, i.e., $F_{\mathrm{IS}}$ (inter individual), $F_{\mathrm{ST}}$ (subpopulations) and $F_{\mathrm{IT}}$ (total population) (Excoffier, 2007).

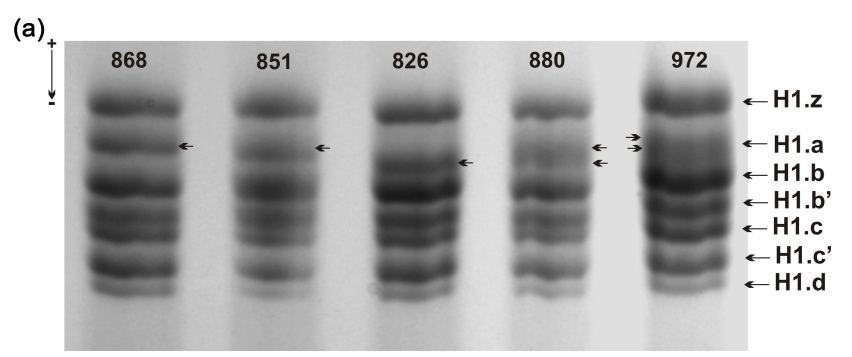

(b)

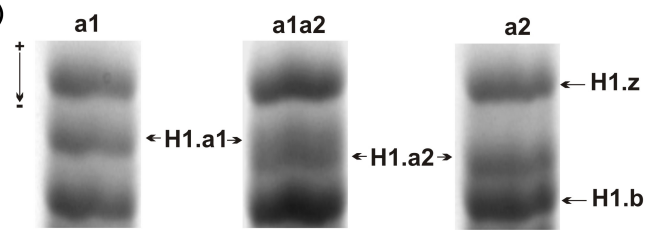

Figure 1. In (a), a fragment of AU-PAGE gel with resolved H1 histones belonging to different quail individuals marked by the numbers. In contrast to the histone H1 subtypes H1.z, H1.b, H1.b' ${ }^{\prime}$ H1.c, H1. $\mathrm{c}^{\prime}$ and H1.d possessing invariable electrophoretic mobility, the altered electrophoretic migration of subtype H1.a is depicted by the arrows located close to the respective protein band. In (b), the histone H1.a phenotypes a1, a2 and a1 a2 formed by the isoforms H1.a1 and H1.a2 differ in the in-gel location with respect to adjacent subtype H1.z and H1.b occupying the same in-gel position.

\subsection{Results}

\subsubsection{Electrophoretic identification of histone $\mathrm{H} 1$.a phenotypic diversity}

The screening of quail erythrocyte $\mathrm{H} 1$ histones with AUPAGE revealed the same in-gel position of subtype H1.b, H1.b', H1.c, H1.c', H1.d, H1.z and a varied localization of the subtype H1.a (Fig. 1a). In the patterns of AU-PAGE, histone H1.a was visible in a single and double form created by more intense and slightly weaker protein bands, respectively. Thus, the heterogeneity of subtype H1.a reflects the presence of differently migrating protein bands belonging to slow isoform H1.a1 and the fast isoform H1.a2 which singly form a homozygous phenotype a1 and a2, respectively, and collectively a heterozygous phenotype, a1 a2 (Fig. 1b). A disparate rate of histone H1.a electrophoretic mobility with AU-PAGE means that its isoforms possess different net charge.

In the screened quail individuals, histone H1.a homozygous phenotypes (a1 and a2) were comparably abundant $(p>0.05)$ occurring at a ratio of about 0.5 in relation to the heterozygous phenotype (a1a2) (Table 1). Whereas the CV values calculated for histone H1 a protein bands were below 0.25 (Table 1), the level of relative variability is low in the case of each histone H1.a phenotype. With various crosses of the individuals representing a parental generation, a codominant inheritance of histone H1.a genotypes was confirmed in a descendant generation (Table 2). 
Table 1. Quantification of histone H1.a phenotypes. An area and the integrated density (mean \pm standard deviation) of histone H1.a protein bands resolved with AU-PAGE was measured to determine the abundance of histone H1.a phenotypes. The measurements were conducted for $10(n=10)$ histone H1.a protein bands of a given phenotype. The level of histone H1.a phenotypes relative variability was determined according to the values of CV.

\begin{tabular}{|c|c|c|}
\hline $\begin{array}{l}\text { Phenotype } \\
\text { H1.a }\end{array}$ & Area/CV & Integrated density/CV \\
\hline a1 & $3501.6 \pm 742.99 / 0.21^{\mathrm{a}}$ & $348956.3 \pm 79090.83 / 0.22^{b}$ \\
\hline $\mathrm{a} 2$ & $3216.4 \pm 654.31 / 0.20^{c}$ & $319939.0 \pm 43262.53 / 0.13^{d}$ \\
\hline $\mathrm{a} 1 \mathrm{a} 2$ & $6369.3 \pm 1230.31 / 0.19^{\mathrm{e}}$ & $688561.5 \pm 137445.67 / 0.19^{f}$ \\
\hline
\end{tabular}

Table 2. The distribution of histone H1. a genotypes in the offspring of differently crossed quail individuals.

\begin{tabular}{lrrrr}
\hline $\begin{array}{l}\text { Type of mating } \\
\text { female } \times \text { male }\end{array}$ & $\begin{array}{r}\text { Progeny } \\
\text { number }\end{array}$ & \multicolumn{2}{c}{$\begin{array}{c}\text { Distribution of genotype } \\
\text { Observed/expected }\end{array}$} \\
\cline { 3 - 5 } & & alal & ala2 & $a 2 a 2$ \\
\hline ala1 $\times a 1 a 1$ & 4 & $4 / 4$ & & \\
$a 1 a 1 \times a 2 a 2$ & 3 & & $3 / 3$ & \\
ala2 $\times a 1 a 1$ & 8 & $6 / 4$ & $2 / 4$ & \\
$a 1 a 2 \times a 1 a 2$ & 4 & $2 / 1$ & $2 / 2$ & $0 / 1$ \\
$a 1 a 2 \times a 2 a 2$ & 5 & & $2 / 2.5$ & $3 / 2.5$ \\
$a 2 a 2 \times a 1 a 1$ & 10 & & $10 / 10$ & \\
$a 2 a 2 \times a 1 a 2$ & 12 & & $4 / 6$ & $8 / 6$ \\
$a 2 a 2 \times a 2 a 2$ & 9 & & & $9 / 9$ \\
\hline
\end{tabular}

\subsection{Population characteristic of histone H1.a phenotypic diversity}

As shown in Table 3, the equivalent participation of histone H1.a phenotypes is characteristic for both the unselected and selected quail line. The distribution of histone H1.a phenotype frequency turned out to be statistically non-significant $\left(\chi^{2}=1.63, p=0.44\right)$ among quail lines. Likewise, an equal distribution of allele frequency $\left(\chi^{2}=0.018, p=0.89\right)$ was detected in the quail lines tested, which were also found to conform to the Hardy-Weinberg expectations $\left(\chi^{2}=1.29\right.$, $p=0.25$ in the control line and $\chi^{2}=1.9, p=0.16$ in the selected population) (Table 3 ).

Whereas Wright's $F$-statistics $F_{\mathrm{ST}}$ index amounts to 0.02 , the population subdivision accounts for $0.2 \%$ of the total genetic variation, indicating negligible genetic differentiation among an unselected and selected quail line. Therefore, only $0.2 \%$ of total genetic variation came from differences between quail lines, in which no excess of heterozygotes $\left(F_{\mathrm{IS}}=\right.$ $0.20)$ was observed. The fact that the low overall inbreeding mean value $\left(F_{\mathrm{s}}=0.19\right)$ is similar to the value of the average within-population inbreeding coefficient $\left(F_{\mathrm{IT}}=0.22\right)$ means that no appreciable inbreeding is present in the quail lines (Table 4).
Table 3. The distribution of histone H1.a phenotypes and alleles among quail lines.

\begin{tabular}{|c|c|c|c|}
\hline \multicolumn{4}{|l|}{ Unselected line } \\
\hline Phenotype & a1 & a2 & a1a2 \\
\hline $\begin{array}{l}\text { Number of individuals } \\
\text { (observed/expected) }\end{array}$ & $10 / 8.17$ & $12 / 10.39$ & $15 / 18.43$ \\
\hline $\begin{array}{l}\text { Frequency of } \\
\text { phenotype } \\
\text { (observed/expected) }\end{array}$ & $0.27 / 0.22$ & $0.32 / 0.28$ & $0.41 / 0.50$ \\
\hline HWE $\chi^{2}=1.29, p=0.25$ & & & \\
\hline Allele & $a^{1}$ & & $a^{2}$ \\
\hline Frequency of allele & 0.47 & & 0.53 \\
\hline \multicolumn{4}{|l|}{ Selected line } \\
\hline Phenotype & a1 & $\mathrm{a} 2$ & a1a2 \\
\hline $\begin{array}{l}\text { Number of individuals } \\
\text { (observed/expected) }\end{array}$ & $11 / 8.67$ & $14 / 11.95$ & $16 / 20.36$ \\
\hline $\begin{array}{l}\text { Frequency of } \\
\text { phenotype } \\
\text { (observed/expected) }\end{array}$ & $0.27 / 0.21$ & $0.34 / 0.29$ & $0.39 / 0.50$ \\
\hline $\mathrm{HWE} \chi^{2}=1.90, p=0.16$ & & & \\
\hline Allele & $a^{1}$ & & $a^{2}$ \\
\hline Frequency of allele & 0.46 & & 0.54 \\
\hline
\end{tabular}

Table 4. Genetic diversity within quail populations.

\begin{tabular}{lrrrrrr}
\hline Quail line & $H_{\text {obs }}$ & $H_{\text {exp }}$ & $F_{\mathrm{S}}$ & $F_{\text {IS }}$ & $F_{\text {ST }}$ & $F_{\text {IT }}$ \\
\hline Unselected & 0.40 & 0.49 & 0.18 & 0.20 & 0.02 & 0.22 \\
Selected & 0.39 & 0.49 & 0.20 & & & \\
\hline
\end{tabular}

$H_{\text {obs }}$ - observed heterozygosity; $H_{\exp }$ - expected heterozygosity;

$F_{\mathrm{S}}$ - subpopulation inbreeding coefficient. Wright's $F$-statistics fixation indices: $F_{\mathrm{IS}}-$ inter-individual; $F_{\mathrm{ST}}-$ subpopulations; and $F_{\mathrm{IT}}-$ total population.

\section{Discussion}

In contrast to the histone $\mathrm{H} 1$ subtypes occurring in a certain bird species only, the histone H1.a is widespread in all tested species (Kowalski and Pałyga, 2017), constituting on average $25 \%$ of a whole histone $\mathrm{H} 1$ complement. Histone H1.a has been repeatedly reported as a polymorphic protein due to the presence of isoforms that may differ in both localization and intensity in the electrophoretic gels. Whereas chicken and duck histone H1.a isoforms (H1.a1 and H1.a2) characterize a disparate migration rate with AU-PAGE pointing to a difference in their net charge (Górnicka-Michalska et al., 2014), a high (phenotype a1) and intermediate (phenotype a1a0) level as well as a lack (phenotype a0) of histone H1.a was detected among the Pharaoh quail individuals. Due to the leaking expression of histone H1.a, several birds containing the minimum amount of protein were also detected (Pałyga, 1998b). It follows that the polymorphism of histone H1.a currently identified in the Japanese quail population resembles that which was already detected in chickens 
(Górnicka-Michalska et al., 2006) and duck (Kowalski et al., 1998) strains, and therefore it is distinct from a characteristic of the quail lines of the variety Pharaoh (Pałyga, 1998b).

According to earlier reports (for a review, see Kowalski and Pałyga, 2012a), the histone H1 polymorphic variants are unequally distributed in the various avian populations, in which a considerably high frequency of one H1 phenotype with a simultaneous low frequency, or a lack, of the second phenotype was observed. Whereas a direct influence of histone $\mathrm{H} 1$ phenotypes on the organisms characteristics and functioning is unknown, it seems that the frequent histone $\mathrm{H} 1$ phenotype preferred in the population may evoke some breeding and/or physiologic effect, in contrast to the rare and/or missing phenotype. A disparate distribution of chicken and duck histone H1.a phenotypes was previously detected between the conservative and breeding avian strains (Górnicka-Michalska et al., 2014). While a phenotype a1 was ubiquitous in all chicken and duck strains tested, at a frequency ranging from 0.6 to 1 , the phenotype a 2 was missing in the production duck flocks and occurred at a frequency of up to 0.35 in the conservative, colorfully plumaged lines of both chickens and ducks (Górnicka-Michalska et al., 2014). A difference in the set of histone H1.a phenotypes was also apparent between the chicken breeds (Górnicka-Michalska et al., 2006). Contrary to totally homozygous populations of egg-laying (Leghorn) and meat (Cornish) breeds exemplified by the presence of the phenotype a1 only, the heterozygous (a1a2) individuals were detected in the dual-purpose breed (Rhode Island Red) raised for eggs and meat. Such disparities in the histone $\mathrm{H} 1$ phenotypes distribution concern not only histone H1.a. As was shown by Kowalski and Pałyga (2014), the phenotype $\mathrm{b} 2$ belonging to the subtype H1.b did not occur in the duck production line, contrary to the histone H1.z phenotype $\mathrm{z} 2$, which is present in the duck conservative groups only. Thus, the peculiar histone $\mathrm{H} 1$ isoform constituting a given phenotype may evoke a special effect in the chromatin milieu promoting its unique local conformation and function (Kowalski and Pałyga, 2016), which affects breeding conditions and physiological features of the organism.

The changes in the allele frequencies of histone H1 subtype H1.a, H1.b and H1.z have already been reported in quail lines divergently selected for the amount of weight loss after transient starvation (Pałyga, 1998a). These alterations concern both decreased and increased frequency of the phenotype b1 and z2, respectively, in the line selected for low reduction in body mass, in contrast to the frequency of phenotype a0, which remained unchanged during the course of selection. Likewise, a correlation of selection with the histone $\mathrm{H} 1$ polymorphic variants was also found in the quail population, in which the frequencies of histone $\mathrm{H} 1$ genotypes (subtype H1.b and H1.z) and phenotypes (subtype H1.d) were significantly different between unselected (control) line and the line selected for a high cholesterol content in the egg yolk (Kowalski et al., 2015). Thus, selection for a quantitative trait might introduce a change in the chromatin structure evoking certain functional consequences, i.e., an altered DNA binding and modulated chromatin condensation, connected with the activity of some of the histone $\mathrm{H} 1$ polymorphic variants. The results gathered in this work indicate, however, that not all histone H1 heterogeneous subtypes are susceptible to the selection. This concerns the histone H1.a presented here, whose polymorphic variants were found to be equally distributed in the unselected and selected quail line. Whereas stability of histone H1.a phenotypes was detected during the selection period, it seems that selection proceeds without influence on the chromatin organization and/or activity remaining under the control of histone H1.a. Despite the mechanism of avian histone $\mathrm{H} 1$ subtypes being obscure, their mode of action might be similar to the mammalian $\mathrm{H} 1$ subtypes. Their common and individual activity, related to DNA and protein interaction as well as to the regulation of gene expression, manifests differently in peculiar cellular processes (for a review, see Herghet and Schneider, 2015; Kalashnikova et al., 2016; Kowalski and Pałyga, 2016a; Parseghian, 2015). Therefore, the function of certain avian H1 subtypes (H1.b, H1.d and H1.z) displaying altered allele frequency in response to selection (Kowalski et al., 2015) might be associated with genetic and/or epigenetic regulation of egg yolk cholesterol content, in contrast to the subtype H1.a, whose phenotypic variants were detected in this work as similarly frequent, irrespective of conducted selection.

\section{Conclusions}

The obtained results demonstrate that qualitative variation of histone H1.a currently identified in Japanese quail corresponds to the one that was previously observed in other species, i.e., chickens and ducks (Górnicka-Michalska et al., 2014), and not resembles histone H1.a quantitative heterogeneity detected in the quail variety Pharaoh (Pałyga, 1998b). In contrast to other histone H1 subtypes (Pałyga, 1998a; Kowalski et al., 2015) whose polymorphic variants were found to significantly differ in the distribution between unselected and selected individuals, the quail histone H1.a phenotypes are equally distributed in both the control and selected line, and both comply with the HardyWeinberg equilibrium. A small genetic divergence of quail lines might indicate no correlation of histone H1.a with a selected trait. It seems that anticipated influence of selection on the chromatin-dependent cellular processes proceeds without an engagement of histone H1.a.

Data availability. The original data are available upon request from the corresponding author.

Competing interests. The authors declare that they have no conflict of interest. 
Edited by: S. Maak

Reviewed by: M. Piscopo and one anonymous referee

\section{References}

Bhan, S., May, W., Warren, S. L., and Sittman, D. B.: Global gene expression analysis reveals specific and redundant roles for $\mathrm{H} 1$ variants, $\mathrm{H} 1 \mathrm{c}$ and $\mathrm{H}_{1}{ }^{\circ}$, in gene expression regulation, Gene, 414 , 10-18, 2008.

Crane-Robinson, C.: Linker histones: history and current perspectives, Biochim. Biophys. Acta, 1859, 431-435, 2016.

Excoffier, L.: Analysis of population subdivision, in: Handbook of statistical genetics, 3rd Edn., edited by: Balding, D. J., Bishop, M., Canings, C., John Wiley \& Sons, England, 980-1013, 2007.

Górnicka-Michalska, E., Pałyga, J., Kowalski, A., and CywaBenko, K.: Sequence variants of chicken linker histone H1.a, FEBS J., 273, 1240-1250, 2006.

Górnicka-Michalska, E., Kowalski, A., and Pałyga, J.: Allelic isoforms of the chicken and duck histone H1.a, Cell. Mol. Biol. Lett., 19, 116-125, 2014.

Happel, N. and Doenecke, D.: Histone H1 and its isoforms: contribution to chromatin structure and function, Gene, 431, 1-12, 2009.

Hansen, J. C.: Human mitotic chromosome structure: what happened to the 30-nm fibre?, EMBO J., 31, 1621-1632, 2012.

Herghet, S. P. and Schneider, R.: The H1 linker histones: multifunctional proteins beyond the nucleosomal core particle, EMBO Rep., 16, 1439-1453, 2015.

Izzo, A., Kamieniarz-Gdula, K., Ramirez, F., Noureen, N., Kind, J., Manke, T., van Steensel, B., and Schneider, R.: The genomic landscape of the somatic linker histone subtypes H1.1 to H1.5 in human cells, Cell Rep., 3, 2142-2154, 2013.

Kalashnikova, A. A., Rogge, R. A., and Hansen, J. C.: Linker histone $\mathrm{H} 1$ and protein-protein interactions, Biochim. Biophys. Acta, 1859, 455-461, 2016.

Kowalski, A.: Nuclear and nucleolar activity of linker histone variant H1.0, Cell. Mol. Biol. Lett., 21, 15, 12 pp., https://doi.org/10.1186/s11658-016-0014-0, 2016a.

Kowalski, A.: A heterogeneity of the pheasant (Phasianus colchicus L.) erythrocyte histone H1 subtype H5, C. R. Biol. 339, 357-363, 2016b.

Kowalski, A. and Pałyga, J.: Chromatin compaction in terminally differentiated avian blood cells: the role of linker histone H5 and non-histone protein MENT, Chromosome Res. 19, 579-590, 2011.

Kowalski, A. and Pałyga, J.: Linker histone subtypes and their allelic variants, Cell Biol. Int., 36, 981-996, 2012a.

Kowalski, A. and Pałyga, J.: High-resolution two-dimensional polyacrylamide gel electrophoresis: a tool for identification of polymorphic and modified linker histone components, in: Gel Electrophoresis - Principles and Basics, edited by: Magdeldin, S., InTech, Croatia, 117-136, 2012b.

Kowalski, A. and Pałyga, J.: Polymorphic linker histone H1 variants in breeding and conservative duck populations, Ann. Anim. Sci., 14, 33-42, 2014.

Kowalski, A. and Pałyga, J.: Modulation of chromatin function through linker histone H1 variants, Biol. Cell, 108, 1-18, 2016.
Kowalski, A. and Pałyga, J.: Distribution of non-allelic histone H1 subtypes in five avian species, Ann. Anim. Sci., 17, 385-398, 2017.

Kowalski, A., Pałyga, J., Górnicka-Michalska, E., and Krajewska, W. M.: Allelic polymorphism of histone H1.a in duck erythrocytes, Biochem. Genet., 36, 183-191, 1998.

Kowalski, A., Pałyga, J., Górnicka-Michalska, E., Bernacki, Z., and Adamski, M.: Phenotypic variation of erythrocyte linker histone H1.c in a pheasant (Phasianus colchicus L.) population, Genet. Mol. Biol., 33, 475-478, 2010.

Kowalski, A., Pałyga, J., and Górnicka-Michalska, E.: Two polymorphic linker histone loci in guinea fowl erythrocytes, C. R. Biol., 334, 6-12, 2011.

Kowalski, A., Pałyga, J., Knaga, S., and Witkowski, A.: A shift in the erythrocyte histone $\mathrm{H} 1$ complement following selection in quail (Coturnix japonica), Czech J. Anim. Sci., 60, 105-115, 2015.

McBryant, S., Lu, X., and Hansen, J. C.: Multifunctionality of the linker histones: an emerging role for protein-protein interactions, Cell Res., 20, 519-528, 2010.

Millãn-Ariño, L., Izquierdo-Bouldstridge, A., and Jordan, A.: Specificities and genomic distribution of somatic mammalian histone H1 subtypes, Biochim. Biophys. Acta, 1859, 510-519, 2016.

Neelin, J. M., Neelin, E. M., Lindsay, D. W., Pałyga, J., Nichols, C. R., and Cheng, K. M.: The occurrence of a mutant dimerizable histone H5 in Japanese quail erythrocytes, Genome, 38, 982-990, 1995.

Pałyga, J.: Distribution of allelic forms of erythrocyte H1 histones in Japanese quail populations divergently selected for amount of weight loss after transient starvation, Biochem. Genet., 36, 7992, 1998a.

Pałyga, J.: Genes for polymorphic H1 histones are linked in the Japanese quail genome, Biochem. Genet., 36, 93-103, 1998 b.

Pałyga, J., Górnicka-Michalska, E., Kowalski, A., anf Książkiewicz, J.: Natural allelic variation of duck erythrocyte histone H1.b, Int. J. Biochem. Cell Biol., 32, 665-675, 2000.

Parseghian, M.: What is the role of histone H1 heterogeneity?, AIMS Biophys., 2, 724-772, 2015.

Pernica, P., Wells, M. G., and Sprules, W. G.: Internal waves and mixing in the epilimnion of a lake affects spatial patterns of zooplankton in a body-size dependent manner, Limnol. Oceanogr., 3, 279-294, 2013.

Piscopo, M., Conte, M., Di Paola, F., Conforti, S., Rana, G., De Petrocellis, L., Fucci, L., and Geraci, G.: Relevance of arginine in the mode of binding of $\mathrm{H} 1$ histones to DNA, DNA Cell Biol., 29, 339-347, 2010.

Roque, A., Ponte, I., and Suau, P.: Interplay between histone H1 structure and function, Biochim. Biophys. Acta, 1859, 444-454, 2016.

Salvati, D., Conforti, S., Conte, M., Swann Matassa, D., Fucci, L., and Piscopo, M.: Self-association of Cheatopterus variopedatus sperm histone H1-like, Relevance of arginine content and possible physiological role, Acta Biochim. Pol., 55, 701-706, 2008.

Th'ng, J. P. H., Sung, R., Ye, M., and Hendzel, M. J.: H1 family histones in the nucleus, J. Biol. Chem., 280, 27809-27814, 2005. 
Woodcock, C. L. and Ghosh, R. P.: Chromatin higher-order structure and dynamics, Cold Spring Harbor Perspect. Biol., 2, a000596, https://doi.org/10.1101/cshperspect.a000596, 2010.
Zhou, B.-R., Jiang, J., Feng, H., Ghirlando, R., Xiao, T. S., and Bai, J.: Structural mechanisms of nucleosome recognition by linker histones, Mol. Cell, 59, 1-11, 2015. 